recommend recognition of this side effect so that careful attention can be paid to oral comfort and hygiene.

The Institute of Cancer Research receives financial support from the Cancer Research Campaign and the Medical Research Council. PJH is supported by the Cancer Research Campaign. We thank Felicity Fleetwood for typing the manuscript.
1 Hanks GW, Hoskin PJ. Opioid analgesics in the management of pain in patients with cancer. A review. Palliative Medicine 1987;1:1-25.

2 Duthie JR, Nimmo WS. Adverse effects of opioid analgesic drugs. Br $\mathcal{F}$ Anaesth 1987;59:61-77.

3 Jaffe JH, Martin WR. Opioid analgesics and antagonists. In: Gilman AG, Goodman LS, Rall TW, Murad F, eds. The pharmacological basis of therapeutics. 7th ed. New York: Macmillan, 1985:498.

4 McCullagh P, Nelder JA. Generalized linear models. London: Chapman and Hall, 1983.

5 Cheater F. Xerostomia in malignant disease. Nursing Mirror 1985; July 17:25-7.

(Accepted 27 February 1989)

\section{Relief care and risk of death in psychogeriatric patients}

\author{
Carolyn Selley, Michael Campbell
}

\begin{abstract}
Psychogeriatric Unit, Moorgreen Hospital, Southampton SO3 3JB Carolyn Selley, MRCPSYCH,
\end{abstract} senior registrar

\section{Department of Medical Statistics and Computing, University of \\ Southampton, \\ Southampton \\ Michael Campbell, PHD, senior lecturer}

Correspondence to: $\operatorname{Dr} C$ Selley, Department of Psychotherapy, Department of Psychiatry, Royal South

Hants Hospital, Southampton SO9 4PE.

Br Med f 1989;298:1223 parisons of mortality are difficult. the time spent in each place.
In a paper on the hazards for elderly people of a single admission for respite and social care Rai et al described a high mortality of $22 \%$. This compared poorly with the mortality for patients admitted with acute illness to geriatric wards, and they concluded that such admissions for relief should be discouraged. ${ }^{1}$ Their paper led to critical correspondence and understandable concern to carers of elderly, chronically sick patients. ${ }^{2} \mathrm{~A}$ major problem in interpreting this paper is that the admission policy in different centres and for different illnesses probably varies, and so direct com-

Relief admissions are widely used in the psychogeriatric unit at this hospital. We studied whether there was an increased risk of a patient dying when admitted to the unit for relief care compared with the risk for that patient at home or elsewhere, allowing for

\section{Methods and results}

We studied case notes of patients aged over 65 admitted to the relicf admission programme from 6 February 1985 to 5 February 1988 who died in that period. A relief admission was defined as an admission arranged solely to allow the carer respite. An admission where the notes indicated physical or psychiatric deterioration as the cause was excluded. Patients were regarded as being on the relief admission programme from when they were first admitted in the period studied. Patients were withdrawn from the programme if they were admitted to long stay hospital care or a residential home. Details of sex, age, and the total number of relief admissions of each patient were obtained. Any physical disability recorded in the notes that was likely to increase the care the patient required or to be a risk to future health was noted.

We obtained the numbers of patients dying during and outside relief admissions during their time on the programme. A death during relief admission was defined as a death occurring while the patient was in hospital or directly occurring because of a condition contracted during relief admission. We calculated the number of days each patient spent in hospital during relief care and the number of days on which they did not receive relief care during the programme. We analysed the differences in mortality for those dying during and outside relief admissions with the Mantel-
Haenszel test and calculated $95 \%$ confidence intervals with Miettinen's test based approximation. ${ }^{3}$

During the three years 48 out of 210 patients died while still on the relief admission programme. They had been admitted for relief care on 218 occasions. All but one set of case notes were traced, and sufficient information was obtained from nurses' notes for this patient to be included. The table shows the results. Taking into account the amount of time that patients did and did not receive relief care, the differences between the observed and expected numbers of deaths were not significant $\left(\chi^{2}=0 \cdot 19, \mathrm{df}=1, \mathrm{p}>0 \cdot 5\right)$. The relative risk of dying during relief care was $1 \cdot 14(95 \%$ confidence interval 0.64 to $2 \cdot 02$ ).

Characteristics of deaths in three years of relief admission programme

\begin{tabular}{lcc}
\hline & $\begin{array}{c}\text { Deaths during } \\
\text { relief care }\end{array}$ & $\begin{array}{c}\text { Deaths not during } \\
\text { relief care }\end{array}$ \\
\hline No of deaths & 19 & 29 \\
Expected No of deaths & $17 \cdot 53$ & $29 \cdot 47$ \\
Sex ratio (men:women) & $1: 2 \cdot 2$ & $1: 0 \cdot 62$ \\
Mean (range) age (years) & $81(65-92)$ & $78(67-89)$ \\
\% With physical disability & 80 & 80 \\
Average total No of relief & $6 \cdot 2$ & $3 \cdot 4$ \\
admissions/person & & \\
\hline
\end{tabular}

^Based on time for which each patient did and did not receive relief care.

\section{Comment}

In terms of mortality alone it remains uncertain whether a single relief admission carries a risk or an advantage. We did not find a significant increase in the risk of death during relief care, but we established the range of relative risk. The exclusion of admissions precipitated by deterioration and the comparison of each subject with himself or herself in the analysis may account for the contrast with Rai et al's work. In addition, our patients may have differed biologically from those patients admitted for respite care to geriatric medical wards. Taken with the clear benefits of this programme described elsewhere ${ }^{4}$ our results support the continued use of relief admissions in this type of service.

We thank Dr C Godber, Dr H Rosenvinge, and Dr D Wilkinson of the Southampton psychogeriatric service, who gave their support and contributed to the work; and Mrs B Humphries for secretarial help.

1 Rai GS, Bielawska C, Murphy P, Wright G. Hazards for elderly people admitted for respite and social care. $\mathrm{Br} \mathrm{Med} \mathcal{f}$ 1986;292:240.

2 Gill $M$. Correspondence on hazards for elderly people admitted for respite and social care. Br Med f 1986;292:482.

Armitage P, Berry G. Statistical methods in medical research. Oxford: Blackwell Scientific Publications, 1987.

4 Pearson N. An assessment of relief hospital admissions for elderly patients with dementia. Health Trends 1988;20:120-1.

(Accepted 23 February 1989) 